\title{
Using Personal Genome TeChnology and Psychometrics to Study the Personality of The NEANDERTHALS
}

\author{
Glenn Geher ${ }^{1}$, Richard Holler ${ }^{1}$, David Chapleau' ${ }^{1}$, Jessica Fell'1, Bernadine

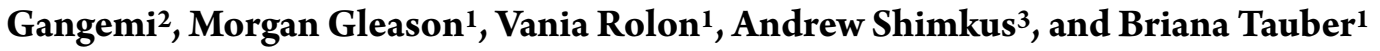 \\ 1State University of New York at New Paltz, New York, USA. \\ ${ }^{2}$ Xavier University, Cincinnati, Ohio, USA. \\ ${ }^{3}$ University of Hartford, West Hartford, Connecticut, USA. \\ geherg@newpaltz.edu
}

\begin{abstract}
The Neanderthals' extinction has been, according to modern biological anthropologists, greatly exaggerated. Research from multiple sources has consistently provided strong evidence of hybridization between ancestral Neanderthals and Ancestrally Modern Humans (AMHs). Personal genome technology, such as that used by the personal-genomic company, 23andMe, provides individuals with information regarding their particular genetic overlap with Neanderthal DNA. Given the fact that most personality traits show some heritable component, this research sought to examine if one's degree of Neanderthal genetic overlap (or Neanderthal Quotient; NQ) is significantly related to a variety of personality traits - traits that, based on anthropological research - may have characterized our ancient Neanderthal cousins. Using an online survey administered to more than 200 adults from around the world who had had their personal genomes mapped, we found that NQ was positively related to such variables as social fear, anxiety, and promiscuity, while being negatively related to scores on a performance-based measure of imaginativeness. Most of these relationships remained significant in regression models that added age and gender into the equations, suggesting that these findings are likely relatively reliable. Findings suggest that high levels of NQ tend to correspond to social fear, autistic tendencies, and depressive tendencies - a constellation of results that is consistent with the conception of Neanderthals as being ill-suited for large-scale social living.
\end{abstract}

Keywords: Neanderthal, personality, personal genome, social anxiety, fear, sociosexuality. 
Recent research into the genetics of the ancient Neanderthals suggests that, in the words of the late Mark Twain, news of their extinction has been greatly exaggerated (Hodgson, Bergely, \& Disotell, 2010; Greene et al., 2010). Modern genomic-analysis techniques have been used to examine similarities and differences between the genomes of the ancient Neanderthals (who reportedly became extinct about 40,000 years ago) with the genomes of anatomically modern humans (AMH). These analyses revealed clear evidence of multiple hybridization events between Neanderthals and AMHs thousands of years ago. Interestingly, only individuals who have post-African-diaspora ancestry show DNA that overlaps with Neanderthal DNA (which is based on a conglomerate model from samples of three different female Neanderthals). Thus, hybridization events must have taken place beyond Africa - likely in Eurasia. Based on this work, we now know that descendants of AMHs who come from Europe and Asia have between 1\% $4 \%$ of their DNA reflecting their Neanderthal ancestors (via these hybridization events).

Given this backdrop, note that the current research is primarily designed to ask an age-old question regarding hominid origins: What were the Neanderthals like? Past work into this question has examined fossilized remains (see Henry, Brooks, \& Piperno, 2010), tools (Karavani \& Smith, 1998), and geographical patterns of DNA dispersion (Mellars, 2004), among other forms of data. Based on studies utilizing a plurality of techniques, past researchers have provided some sense of the personality constellations that may have typified the ancient Neanderthals (see Wynn \& Coolidge, 2004; Tattersall, 2002). In short, (for reasons elaborated in the next section) these researchers paint a picture of Neanderthals as relatively unintelligent, uncreative, aggressive, and emotionally stoic. Further, there is some reason to believe that they may have displayed behaviors that reflect those from the autistic spectrum (Reser, 2011).

The current study was designed to add to the insights we have regarding Neanderthal psychology. By using a technique that combines modern human genomics along with current psychometrics via personality psychology, the current study serves to expand our understanding of the ancient Neanderthals using a novel methodological approach. In short, the current study examined the correlations between Neanderthal Overlap (or Neanderthal Quotient; NQ) with a variety of potentially relevant personality traits in a sample of current adults who have had their genomes mapped. This methodology was employed as a novel way to explore the possible personality profiles of our ancient Homo relatives.

\section{What We Know About the Psychology of the Neanderthals}

Exploring the psychology of an extinct (or primarily extinct) species is a speculative business for sure. This said, as mentioned prior, based on various methodologies, past scholars into this question have come up with several informed portraits of Neanderthal psychology. For instance, evidence of their tool use showed that they were not as good as their Homo sapien counterparts at coming up with novel tools - so we believe that they may have generally lacked creativity (See Wynn \& Coolidge, 2004). Further, analyses of their hunting practices suggested that they probably had effective long-term memory (as there is evidence that they regularly went on extended hunts and found their way back) - 
but their short-term memory (again, based on the simplicity of their tool use) was likely limited.

Osteopathic data suggest that the Neanderthals often took blows from conspecifics suggesting that they likely fought a lot (Wynn \& Coolidge, 2012). They may well then have been aggressive and somewhat anti-social. Further, this evidence is often taken as indicating that they may have been relatively risky in their behavior. Based on recent evolution-based conceptions of risky behavior (see Wilkes et al., 2014), such riskiness may cut across a variety of domains including physical, social, and sexual areas, among others.

However, when it comes to the sociality of the Neanderthals, the data are somewhat complex. Socially, there is reason to believe that the Neanderthals had strong kin-based connections - and they cared deeply about individuals within their groups (Sommer, 2009). Information on this front comes from the widespread evidence of Neanderthal burials, found across a diverse range of geographical areas. Such burials were consistently done with care - showing a concern for particular individuals. So perhaps Neanderthals had some level of compassion - particularly within kin units.

From an evolutionary behavioral perspective, one fact that is particularly intriguing about the Neanderthals pertains to their group size. AMHs formed groups of up to 150 individuals for generations before agriculture entered the scene (see Dunbar, 1992). Importantly, these groups were mixed in terms of relatedness - AMH groups include a mixture of kin and non-kin - and the basics of our social psychology seems to be largely rooted in negotiating such social contexts (see Geher, 2014). This largely entails building bonds with non-kin and kin alike - and forming long-standing coalitions accordingly. David Sloan Wilson (2007) talks about this fact about AMHs as a landmark element of our evolution. Once human beings started forming coalitions with non-kin, group size increased. And once our ancestors started to live in larger groups, they were capable of utilizing resources associated with large groups - such as building armies - in both literal and metaphorical fashions. One we started to form large non-kin-based in-groups, the stage was set for the advent of civilization (See Bingham \& Souza, 2009).

Research into the issue of Neanderthal group size suggests that the Neanderthals never made this great evolutionary leap (see Vallverdu, 2010). Such data suggest that the typical group size for Neanderthals was about 8-10 individuals. Thus, Neanderthals would have never experienced strong evolutionary pressures to develop attributes that primarily help one negotiate large-scale human societies.

This constrained-group-size feature of the Neanderthals leads us to hypothesize that the Neanderthals would be quite lacking in socially oriented behaviors and traits. This prediction is consistent with work on predictors of social anxiety in modern adults showing that a lack of extensive early socialization tends to predict social anxiety later in life (Teacherman \& Allen, 2007). Based on what we know about the social worlds of Neanderthals, they likely had relatively limited opportunities for social interactions in early life compared with Ancestrally Modern Humans.

Thus, the many traits that are so critical for modern humans needed to negotiate our complex social worlds would likely never have evolved to typify the Neanderthals. Thus, they likely did not have strong social connections outside of their kin units, they may have been highly xenophobic, they may not have been particularly empathetic, and they 
may have been high in social anxiety (as they would not have had regular social experiences that would, over time, tone down social anxiety).

\section{The Current Study}

The current study is designed to elaborate on our understanding of the Neanderthal personality. Modern personal genome companies such as 23 andMe provide individuals with an estimate of their Neanderthal Overlap (NQ). This study surveyed a large number of adults who had had their genomes mapped. These participants then completed various questionnaires designed to test the following predictions. First, we predict that NQ would be positively correlated with emotional instability. Next, we predict that NQ would be positively correlated with risky and promiscuous sexual behavior (based on the connections between evolution-based risk behavior and sexuality (Wilkes et al., 2014). In terms of creativity, we predicted that NQ would be negatively correlated with scores on a performance-based measure of imaginativeness (a facet of creativity). We also predicted that NQ would be positively correlated with markers of autism, anxiety, bipolar tendencies, and depressive tendencies. Finally, we predicted that NQ would be negatively correlated with the tendency to have a supportive social network.

\section{METHODS}

A survey was created using Qualtrics software. A pre-requisite for participation was that one had to have had his or her genome mapped by 23andMe or a comparable company one that provides the index of Neanderthal Quotient (NQ). These personal genome companies map the entire genomes of individuals and provide detailed reports on the genomes as well as known correlates associated with particular genetic constellations.

\section{Participants}

Over 700 participants started this survey. However, the final $\mathrm{N}$ was near 200 for most variables. Most participants did not complete the survey - likely as a result of its lengthy nature (the survey took approximately an hour to complete). The $\mathrm{N}$, then, varies from variable to variable and analysis to analysis (based on which participants completed which scales). The largest $\mathrm{N}$ for any of our analyses was 210 - and this includes 100 males and 110 females (all of whom were 18 or older). The smallest $\mathrm{N}$ in any of our analyses is 87.

While we surveyed individuals from around the world, our participants largely ended up being of caucasion European descent. In fact, $89 \%$ of our sample reported being "white and of European descent." The mean age was $26.32(\mathrm{SD}=14.75)$ and the ages ranged from 18-72.

\section{Measures and Procedure}

Members of the lab team posted the Qualtrics link in a variety of online venues (websites, Facebook groups, etc.). The survey included various scales (demarcated in Table 1). These scales includedGosling et al.s (2003) Ten Item Personality Scale to 
Table 1: Summary of all outcome measures.

\begin{tabular}{|c|c|c|}
\hline Variable & Sub-Facet & Measuring Instrument \\
\hline \multirow[t]{4}{*}{ Sociosexual Orientation (SOI-R) } & & $\begin{array}{l}\text { Penke’s Revised Sociosexual } \\
\text { Orientation Inventory (2008) }\end{array}$ \\
\hline & Behavior & \\
\hline & Attitude & \\
\hline & Desire & \\
\hline \multirow[t]{3}{*}{ Social Anxiety } & & $\begin{array}{l}\text { Liebowitz Social Anxiety Scale } \\
\text { (1987) }\end{array}$ \\
\hline & Fear & \\
\hline & Avoidance & \\
\hline \multirow[t]{6}{*}{ Big Five Personality Traits } & & $\begin{array}{l}\text { Gosling's (2003) Brief Inventory of } \\
\text { Personality }\end{array}$ \\
\hline & Openness & \\
\hline & Consciousness & \\
\hline & Extraversion & \\
\hline & Agreeableness & \\
\hline & Neuroticism & \\
\hline Depressive Tendencies & & $\begin{array}{l}\text { Kessler Psychological Distress Scale } \\
(2002)\end{array}$ \\
\hline Bipolar Tendencies & & $\begin{array}{l}\text { Bipolar Spectrum Diagnostic Scale } \\
\text { (revised) by Ghaemi et al., } 2005\end{array}$ \\
\hline \multirow[t]{6}{*}{ Autism } & & $\begin{array}{l}\text { Autism-Spectrum Quotient by } \\
\text { Baron-Cohen (2001) }\end{array}$ \\
\hline & Social Skill & \\
\hline & Attention Switching & \\
\hline & Attention to Detail & \\
\hline & Communication & \\
\hline & Imagination & \\
\hline Imaginativeness & & Created Measure \\
\hline
\end{tabular}

measure the Big Five personality traits (openness, conscientiousness, extraversion, agreeableness, and neuroticism). This scale included 10 items on a $1-5$ point likert scale 
(participants were asked to indicate how much they agreed or disagreed of each trait that described them). We also included the Bipolar Spectrum Diagnostic Scale-R; BSDS-R (Ghaemi et al., 2005). This inventory included 20 items that had the participants indicate either "Yes" or "No" to. The difference between this scale and the original BSDS is that the sentences that compose the passage used in the original BSDS were broken down into individual items, as well as changing out the original answer choices of, for example, "This story fits me very well or almost perfectly" with dichotomous choices of "Yes or No." To measure sexual tendencies, we included the Revised Socio-sexual Orienation by Penke (2008), which included 9 items on a 1-4 scale (participants were asked to indicate how much they agreed or disagreed with statements about their sexual behavior, attitude, and desire). To address social anxiety, we included the Liebowitz Social Anxiety Scale (1987), which included two 24-item inventories on a 1-4 scale on (1) social fear and (2) social avoidance (participants were asked to indicate how much they agreed or disagreed that each statement that described them). Depressive tendencies was tapped with the Depressive Tendencies (Psychological Distress Scale) by Kessler (2002). On a scale from 1-5, participants had to indicate how much they agreed with each of the 10 statements that described their mood in the last 30 days. Autistic tendencies was measured via the Autism Spectrum Quotient by Baron-Cohen (2001) that measured one's social skill, attention switching, attention to detail, communication, and imagination. This 50-item inventory was scored on a scale 1-4 (participants were asked to indicate how much they agreed or disagreed with statements about their behavior). Finally, an index of imaginativeness was created by the research team for this study. For this performance-based measure, participants wrote captions for two New Yorker cartoons and three judges rated each on a $0-4$ scale of how imaginative each caption was. Strong reliability was found across the judges (Cronbach's alpha $=.79$ ); the mean ratings of the judges were used as the participant's scores.

\section{RESULTS}

The primary research question here pertains to whether NQ measured vis a vis personal genome technology (e.g., 23andMe) is significantly related to various indices of personality, social, and emotional functioning. The analytical strategy was as follows: First, zero-order correlations were computed between NQ and composite scores for the several outcome variables included in this study.

In the initial analyses, none of the correlations emerged as significant (see Table 2). In fact, given the large number of analyses conducted, it was unclear if the findings that did emerge were beyond chance expectations.

Table 2: Zero-Order Correlations between Outcome Variables and Neanderthal Quotient.

\begin{tabular}{lcc}
\hline \multicolumn{1}{c}{ Subscale } & $\mathbf{N}$ & Correlation $(\boldsymbol{r})$ with \\
\hline Extraversion & & $\mathbf{N Q}$ \\
Agreeableness & 87 & -.07 \\
Conscientiousness & 113 & -.09 \\
Neuroticism & 127 & -.06 \\
Openness & 106 & .06 \\
Fear & 140 & -.06 \\
Avoidance & 146 & .11 \\
Depression & 139 & .11 \\
Bipolar & 147 & .13 \\
Autism & 106 & .11 \\
Imagination & 133 & .13 \\
\hline
\end{tabular}


The pattern of results in these initial correlations were suggestive that perhaps targeted sub-items of the scales would be predictive of NQ in a way that is consistent with our predictions. For instance, NQ was positively related to neuroticism, social fear, social avoidance, depressive tendencies, bipolar tendencies, and autistic tendencies. Similarly, the NQ was negatively related to extraversion, agreeableness, and imagination. While these relationships were not significant, the fact that the patterns were strongly in directions consistent with our predictions led us to probe further.

To address this issue from this point, we worked to create finely tuned subscales that, based on scale-analysis processes, demonstrated themselves to be abbreviated yet reliable markers of the various constructs included. This process was conducted by (a) correlating NQ with each individual item from the various outcome measures and then (b) creating clusters of items within measures that were both correlated with NQ and correlated with one another. Mini-subscales for various outcome measures were then created. Next the lab team conducted Cronbach's alpha analyses to determine if this process led to the creation of internally reliable measures. Generally speaking, the minisubscales that were created had alphas that surpassed or approached standard levels of acceptability (see Table 3).

Table 3: Psychometrically Derived Mini-Subscales for Outcome Measures.

\begin{tabular}{|c|c|c|c|}
\hline $\begin{array}{l}\text { Mini-Subscale } \\
\text { Cluster }\end{array}$ & $\begin{array}{l}\text { Number } \\
\text { of Items }\end{array}$ & Items & $\begin{array}{c}\text { Chronbach's } \\
\text { alpha }\end{array}$ \\
\hline SOI-R & 2 & $\begin{array}{l}\text { How often do you have fantasies about having sex } \\
\text { with someone you are not in a committed } \\
\text { romantic relationship with? } \\
\text { How often do you experience sexual arousal when } \\
\text { you are in contact with someone you are not in a } \\
\text { committed romantic relationship with? }\end{array}$ & .82 \\
\hline Fear & 6 & $\begin{array}{l}\text { Talking to people in authority } \\
\text { Working while being observed } \\
\text { Calling someone you don't know very well } \\
\text { Talking with people you don't know very well } \\
\text { Meeting strangers } \\
\text { Expressing a disagreement or disapproval to } \\
\text { people you don't know very well }\end{array}$ & .87 \\
\hline Avoidance & 5 & $\begin{array}{l}\text { Calling someone you don't know very well } \\
\text { Talking with people you don't know very well } \\
\text { Meeting strangers } \\
\text { Speaking up at a meeting } \\
\text { Trying to pick up someone }\end{array}$ & .73 \\
\hline $\begin{array}{l}\text { Depressive } \\
\text { Tendencies }\end{array}$ & 2 & $\begin{array}{l}\text { During the last } 30 \text { days, about how often did you } \\
\text { feel nervous? } \\
\text { During the last } 30 \text { days, about how often did you } \\
\text { feel so nervous that nothing could calm you } \\
\text { down? }\end{array}$ & .74 \\
\hline $\begin{array}{l}\text { Bipolar } \\
\text { Tendencies }\end{array}$ & 2 & $\begin{array}{l}\text { During these high periods do you increase your } \\
\text { alcohol or non-prescription drug use? } \\
\text { During these high periods do you increase your } \\
\text { alcohol or non-prescription drug use? }\end{array}$ & .68 \\
\hline Autism & 5 & $\begin{array}{l}\text { I frequently get so strongly absorbed in one thing } \\
\text { that I lose sight of other things } \\
\text { I find social situations easy } \\
\text { I find it difficult to work out people's intentions } \\
\text { I enjoy meeting new people } \\
\text { I am a good diplomat }\end{array}$ & .15 \\
\hline
\end{tabular}


Our next step was to compute zero-order correlations between NQ and all of these psychometrically created mini-subscales. These findings are reported in Table 4. Generally, NQ was significantly related to these scales in each case. For instance, NQ was positively related to fear in social situations $(\mathrm{r}(152)=.22, \mathrm{p}<.01)$. The full set of correlations is found in Table 4. Note that we use one-tailed tests in these analyses, largely as each of these analyses is based on a priori predictions regarding the correlates of NQ. One-tailed tests are appropriate for situations with a priori predictions. This issue is addressed in the Discussion.

Table 4: Correlations between Neanderthal Quotient and Psychometrically Created Outcome Variables.

\begin{tabular}{|c|c|c|c|c|c|c|c|}
\hline & Fear ${ }^{1}$ & SOI-R ${ }^{2}$ & Avoidance $^{3}$ & Dep $^{4}$ & Bipolar 5 & Autism 6 & Imaginativeness 7 \\
\hline NQ & $.22^{* *}$ & $.15^{*}$ & .09 & $.20^{* *}$ & $.22^{* *}$ & $.23^{* *}$ & $-.12^{*}$ \\
\hline $\mathbf{N}$ & 151 & 175 & 148 & 148 & 129 & 140 & 210 \\
\hline \multicolumn{8}{|c|}{${ }^{*} p<.05 ;{ }^{* *} p<.01$ (one-tailed) } \\
\hline $\begin{array}{l}{ }^{1} \text { Base } \\
{ }^{2} \text { Base } \\
\text { B Base } \\
{ }^{4} \text { Base } \\
{ }^{5} \text { Base } \\
{ }^{6} \text { Base } \\
{ }^{7} \text { Base }\end{array}$ & $\begin{array}{l}\text { d on six } \\
\text { d on tw } \\
\text { d on fiv } \\
\text { d on th } \\
\text { d on tw } \\
\text { d on fiv } \\
\text { d on av }\end{array}$ & $\begin{array}{l}\text { Likert-sc } \\
\text { Likert-s } \\
\text { Likert-s } \\
\text { ee Likert- } \\
\text { dichoto } \\
\text { Likert-s } \\
\text { raged rati }\end{array}$ & $\begin{array}{l}\text { le items rangi } \\
\text { ale items ran } \\
\text { ale items rang } \\
\text { cale items rai } \\
\text { hous-scale ite } \\
\text { ale items rang } \\
\text { ggs made by t }\end{array}$ & $\begin{array}{l}\text { from } 1- \\
\text { from } \\
\text { from } 1 \\
\text { hg from } \\
1=\text { Yes, } \\
\text { from } 1 \\
\text { e judge }\end{array}$ & No & & \\
\hline
\end{tabular}

Next, we computed several standard multiple regression analyses. The main point of these analyses was to see if NQ remained a significant predictor of each outcome measure in light of other potentially relevant predictor variables. Given how novel this particular research question is, there were no obvious predictor variables from a conceptual standpoint to include. This said, we asked participants for both their age and their gender. Given how ubiquitous these variables are in predicting behaviors across all human domains, we thought that including these two variables in the regressions would allow for a fair statistical test of whether NQ stands up as a significant predictor of each outcome variable.

In sum, seven such regression analyses were conducted. For each such analysis, the total $\mathrm{R}^{2}$ was significant, meaning that the set of predictors as a whole predicted a significant amount of variability in the outcome measure. Further, for 5 of these analyses, NQ remained a significant predictor of the outcome variable. Further, there were no suppression effects - in other words, the direction of the relationship between NQ and each outcome variable remained the same as the direction that was found in the zeroorder correlation.

The regression analysis with fear of strangers as the outcome variable provides a nice example of the general pattern of findings. Here, NQ was positively related to fear of strangers. In the regression, this effect remained. Interestingly, gender was also related to 
this variable (males were more fearful of strangers than were females) and age was negatively related to this variable (as one gets older, he or she becomes less fearful of strangers).

Table 5: Predicting Fear from Neanderthal Quotient, Age, and Gender.

\begin{tabular}{lccc}
\hline \multicolumn{1}{c}{ Criterion Variable: Social Fear } & & \\
\hline & Predictor Variables & b & B \\
\cline { 2 - 4 } Gender ${ }^{1}$ & 1.48 & $.19^{*}$ \\
Age & -.08 & $-.28^{*}$ \\
Neanderthal Quotient & 1.62 & $.19^{*}$ \\
\hline $\mathrm{R}^{2}=.14^{*} ; \mathrm{F}(3,147)=8.20$ & & \\
\hline${ }^{*} p>.05 ;{ }^{1}$ males $=1$ and females $=2$ & &
\end{tabular}

\section{DISCUSSION}

The Neanderthals did not truly go extinct some 40,000 years ago. Rather, a small subset of them interbred with AMHs who were just like us - and they live on today in the genomes of billions of us (see Hodgson et al., 2010). Given how different the Neanderthals were from AMHs in so many ways, it makes sense that while they likely shared much with AMHs in terms of behavioral and personality features, they may have also varied from us in terms of several basic personality traits - traits that consistently show relatively high levels of heritability as is true of most personality traits (see Larsen \& Buss, 2013). Thus, if Neanderthals differed from us in their genetic makeup, it makes sense that they would have differed from us in terms of basic personality attributes as well.

Modern personal genome technologies allow us to obtain an estimate of how much one's particular genome overlaps with the genomes of these ancient cousins of ours. In short, technologies utilized by such companies as 23andMe provide "Neanderthal Overlap" estimates (or Neanderthal Quotient estimates; NQ per the terminology used here). The general paradigm of the current research is to see if this NQ variable is significantly related to various personality attributes - attributes that, based on past research regarding the Neanderthals, should be expected to show significant relationships with NQ.

For instance, prior theories regarding the personalities of Neanderthals suggested that they were relatively aggressive, risky, and socially limited (given the limited nature of their social worlds). Thus, we predicted that NQ would be positively related to aggressiveness and riskiness while concurrently mapping onto an inept and perhaps fearful approach to social situations.

Clearly with novel research like this, we should not expect large effect sizes. If NQ does predict features of the personality traits of modern humans, we should not expect these relationships to be particularly large. This said, after working to closely and 
carefully create psychometrically based subscales that capture the essences of several of our measures, we ended up finding that NQ was, in fact, related to several such personality traits in the directions predicted by the guiding principles of this research. For instance, based on zero-order correlations, NQ was positively related to fear in social situations, depression, bipolar tendencies, and autistic tendencies. Further, NQ was positively related to sexual promiscuity and negatively related to scores on a performance-based measure of imaginativeness. Additionally, for five of seven such variables, NQ served as a significant predictor when controlling for the effects of both age and gender, suggesting that NQ may be a significant independent predictor of these traits even when controlling for such ubiquitous predictor variables of human behavior (age and gender). In short, when predicting modern human personality, NQ serves as a contributive matter.

In particular, NQ seems to be related to markers of social adjustment. Indeed, the strongest effects we obtained were related to social fear, depressive tendencies, bipolar tendencies, and autistic tendencies. Given that Neanderthals did not have what was needed to create non-kin-based civilizations, it may well be that individuals who show high NQ are slightly more psychologically mismatched to modern environments than their low NQ counterparts.

\section{Limitations and Future Research}

This research is admittedly novel in its approach and, as such, the findings here ultimately need verification in the form of replication studies from other labs around the world. The sample we obtained was predominantly comprised of white, educated adults from North America. Further, the current research did not get into the nuances associated with particular geographical areas (such as Turkey and Spain) that have longstanding known populations of Neanderthals. Perhaps future research can more carefully explore the role of region of ancestry as it relates both NQ and of the personality traits of individuals. This limitation partly pertains to the biased nature of our sample. In spite of our efforts to obtain a diverse sample, nearly $90 \%$ of our sample reported being "white and of European descent." As such, we were truly unable to examine the effects of ethnic background.

This research also suffers from the same issues of self-report that plague much work in the behavioral sciences. In our efforts to obtain a large sample of individuals who met the requisite criteria for this research, we utilized an online survey approach disseminated broadly. A shortcoming of this methodology necessitates that we did not have actual behavioral data but, rather, self-reported date - which may be subject to various biases. With this in mind, a suggestion for future research would be to examine actual behavioral outcomes that may be empirically connected to NQ. To the extent that any personality measure matters, it should predict actual behavioral outcomes (see Larsen \& Buss, 2013). Future work that examines how NQ may relate to behavioral outcomes related to the kinds of dimensions studied here (e.g., social fear, promiscuity, anxiety, etc.) could have the capacity to provide important insights into the real-world effects of NQ on our modern-day social worlds.

Not only is this research self-report based, but it is correlational in nature. Clearly, an experiment designed to assess the effects of NQ on behavior would allow for more 
internal validity than is found in this study. This said, such a study would be impossible to conduct - as it would necessitate manipulating people to be either high or low in Neanderthal DNA. Thus, all of the standard cautions that go along with correlational research, include the inability make causal inferences, must be noted.

The primary findings of this research are based on correlations between NQ and researcher-created subscales regarding the criterion measures. Our initial analyses examining zero-order correlations between NQ and the a priori subscales did not yield significant correlations. As mentioned in the Results, however, they did yield correlations that were in the directions that we predicted - which is why we probed further and created empirically determined a posteriori subscales. This said, to be sure, this fact is a limitation of our research. It may well be the case that effects of NQ on modern personality traits exist but are relatively small.

Also, note that we used one-tailed tests given that our predictions were made in an a priori fashion. This said, to be conservative, given the exploratory nature of this work, it might make sense to have used two-tailed tests simply out of caution. Note that here if we examine the results via two-tailed tests, NQwould, then, not be significantly related to scores on the sociosexuality and the imagination indices. Thus, these correlations are likely treated best with caution.

\section{Bottom Line}

About 40,000 years ago, Homo sapiens became the dominant form of hominid across the globe - and Neanderthals took a backseat in the history of our species. Modern genomics research (e.g., Hodgson et al., 2010) shows that, unlike what was previously thought, the demise of the Neanderthals on this planet was not exactly a typical extinction. In fact, for thousands of years, some degree of hybridization was taking place between the Neanderthals and AMHs. And many of us have the marks of these hybridizations in our DNA right now. Further, people vary from one another in terms of their NQ. In exploring the personality correlates of $\mathrm{NQ}$ this research found that NQ does, in fact, show small but significant relationships with several personality variables in ways that are predicted from existing evolution-based models of the Neanderthals. Thus, in trying to determine how socially fearful, anxious, or promiscuous one is, part of the answer may be something that psychologists likely have never thought of until now: The answer may partly reside in how much Neanderthal DNA that person has in his or her genome.

This research advances a novel methodology that integrates personal genome technology, evolutionary psychology, personality psychology, and psychometrics. As such, this work may provide a roadmap for integrating these areas in future work in the human behavioral sciences.

\section{ACKNOWLEDGEMENT}

Thanks to Dr. Todd Disotell, whose EvoS talk on Neanderthal hybridization during the SUNY New Paltz EvoS Seminar Series of 2013 provided the ideas and inspiration for this research. Thanks also to SUNY New Paltz's Alice Andrews for suggesting the ideas that shaped the basic methodology and conceptual framework this research. 


\section{REFERENCES}

Baron-Cohen, Wheelwright, S., Skinner, R., Martin, J. \& Clubley, E. (2001). The AutismSpectrum Quotient (AQ): Evidence from Asperger Syndrome/High-Functioning Autism, Males and Females, Scientists and Mathematicians. Journal of Autism and Developmental Disorders, 31(1), 5-17.

Bingham, P.M., \& Souza, J. (2009). Death from a distance and the birth of a humane universe. Lexington, KY: BookSurge Publishing.

Dunbar, R.I.M. (1992). Neocortex size as a constraint on group size in primates. Journal of Human Evolution, 22(6), 469-493. DOI

Geher, G. (2014). Evolutionary Psychology 101. New York: Springer.

Ghaemi, S.N., Miller, C.J., Berv, D.A., Klugman, J., Rosenquist, K.J., \& Pies, R.W. (2005). Sensitivity and specificity of a new bipolar spectrum diagnostic scale. Journal of Affective Disorders, 84 (2-3), 273-277. DOI

Gosling, S. D., Rentfrow, P. J., \& Swann, W. B., Jr. (2003). A Very Brief Measure of the Big Five Personality Domains. Journal of Research in Personality, 37, 504-528. DOI

Green R.E., Krause, J., Briggs, A.W., Maricic, T., Stenzel, U., Kircher, M. ... Pððbo S. (2010). A draft sequence of the Neanderthal genome. Science, 328, 710-722. DOI

Henry, A.G., Brooks, A.S., \& Piperno, D.R. (2010). Microfossils in calculus demonstrate consumption of plants and cooked foods in Neanderthal diets (Shanidar iii, Iraq; spy I and ii, Belgium). Proceedings of the National Academy of Sciences, 1-6. DOI

Hodgson, J. A., Bergey, C. M, \& Disotell, T. R. (2010). Neanderthal genome: The ins and outs of African genetic diversity. Current Biology, 20, 517-519. DOI

Karavanic, I., \& Smith, F. H. (1998). The middle upper Paleolithic interface and the relationship of Neanderthals and early modern humans in the Hrvatsko Zagorje, Croatia. Journal of Human Evolution, 3, 223-248. DOI

Kessler, R.C., Andrews, G., Colpe, L.J., Hiripi, E., Mroczek, D.K., Normand, S.L....Zaslavsky, A.M. (2002) Short screening scales to monitor population prevalences and trends in non-specific psychological distress. Psychological Medicine, 32, 959-956.

Larsen, R., \& Buss, D. M. (2013). Personality Psychology. New York: McGraw Hill

Liebowitz, M. R. (1987). Social phobia. Modern Problems of Pharmacopsychiatry, 22, 141-173. DOI

Mellars, P. (2004). Neanderthals and the modern human colonization of Europe. Nature, 432, 461-465. DOI

Penke, L., \& Asendorpf, J. B. (2008). Beyond global sociosexual orientations: A more differentiated look at sociosexuality and its effects on courtship and romantic relationships. Journal of Personality and Social Psychology, 95, 1113-1135. DOI

Sommer, J. D. (1999). The Shanidar IV "flower burial": A re-evaluation of Neanderthal burial ritual. Cambridge Archaeological Journal, 9, 127-129. DOI

Tattersall, I., 2002. The Monkey in the Mirror: Essays on the Science of What Makes us Human. Harcourt, New York.

Teachman, B. A., \& Allen, J. P. (2007). Development of Social Anxiety: Social Interaction Predictors of Implicit and Explicit Fear of Negative Evaluation. Journal of Abnormal Child Psychology, 35(1), 63-78. DOI

Vallverdú J., Vaquero, M., Cáceres, I., Allué, E., Rosell, J., Saladié, P., ... Carbonell, E. (2010). Sleeping Activity Area within the Site Structure of Archaic Human Groups: Evidence from Abric Romaní Level N Combustion Activity Areas. Current Anthropology, 51(1), 137-145. DOI 
Wilke, A., Sherman, A., Curdt, B., Mondal, S., Fitzgerald, C., \& Kruger, D.J. (2014). An Evolutionary Domain-Specific Risk Scale. Evolutionary Behavioral Sciences, 8, 123-141. DOI

Wilson, D. S. (2007). Evolution for everyone. New York: Delacorte Press.

Wynn, T., \& Coolidge, F. L. (2004). The expert Neanderthal mind. Journal of Human Evolution, 46, 467-487. DOI

Wynn, T. \& Coolidge, F.L. (2012). How to Think Like a Neandertal. New York: Oxford University Press. 